\title{
Comparative study of effects of buprenorphine or clonidine as adjuvants to local anesthetics (bupivacaine $0.25 \%$ ) for supraclavicular brachial plexus block
}

\author{
Bharat Paliwal $^{1}$, Rakesh Karnawat ${ }^{2}$ \\ ${ }^{1}$ (Department of anesthesia and critical care, Dr.S.N.medical college and associated group of hospitals, India) \\ ${ }^{2}$ (Department of anesthesia and critical care, Dr.S.N.medical college and associated group of hospitals, India)
}

\begin{abstract}
Adjuvant to local anesthetics have been tried to enhance analgesic profile. Opioids prolong analgesia but have unfavorable side effect profile. So search for non-opioid with comparable analgesic duration and minimal side effect continues. Hence our study aims to compare Buprenorphine; an opioid similar in structure to morphine but approx. 33 times more potent, to a novel drug Clonidine; an imidazoline derivative with $\alpha 2$-adrenergic agonistic activity. No study comparing the two drugs has been found.

Settings and Design: A total of 60 patients belonging to ASA status I \& II posted for orthopedic upper limb surgery were enrolled and randomly divided into three Groups of 20 each. All patients received $20 \mathrm{ml}$ Bupivacaine $(0.5 \%)$ in supraclavicular brachial plexus block. Group corresponding adjuvant and normal saline were added to make total solution to $40 \mathrm{ml}$. VAS score and other block characteristics were observed at fixed intervals for 24 hours post operatively. "GraphPad Prism version 5.03" used for descriptive, analytic and comparative statistics.

Results: Onset of sensory block was significantly delayed in clonidine group (Group BC). Analgesia lasted significantly longer in buprenorphine group (Group BB).VAS scores were found to be better in Group BB and $B C$ and these score was lower than Group B (bupivacaine alone)except at $24 \mathrm{hr}$. Time to first rescue analgesia and total number of doses were significantly lower in Group BB and Group BC. Incidence of nausea, vomiting and sedation were more in Group BB.
\end{abstract}

Conclusions: Buprenorphine and clonidine are acceptable adjuvants.

Keywords:- Bupivacaine, Buprenorphine, Clonidine, Supraclavicular brachial plexus block,

I. Introduction:

The Supraclavicular brachial plexus block with local anesthetic is one of the most commonly employed regional nerve block technique for upper limb surgery. However, large volume of local anesthetic required to produce desirable effects may result into systemic side effects. A variety of adjuvant has been added to increase analgesia and reduce total dose of local anaesthetic used.

Buprenorphine's prolonged analgesic benefit has been reported with brachial plexus block [1-3]. Some of these also report side effects in form of increased pruritis and nausea [4]. Clonidine appears to have significant analgesic benefit when used in doses up to $150 \mu \mathrm{g}$ at the same time not having the serious side effect profile associated with the use of narcotics. Of the six studies using clonidine as an adjunct, five were supportive [5-10] and only one was negative [11]. Only one study showed adverse effect in form of sedation, hypotension and bradycardia, but that followed the use of doses greater than $150 \mu \mathrm{g}[5]$.

Data on the effects of adding clonidine or buprenorphine to a solution of $40 \mathrm{ml}$ of $0.25 \%$ bupivacaine on postoperative analgesia characteristics of a brachial block in patients undergoing upper limb surgery are scarce and no comparative study of the two exists. Thus this randomized prospective study was done primarily to assess the extension in post operative duration of analgesia, if so obtained. In addition, the brachial plexus block characteristics was also compared along with the side effects, if any.

\section{Subjects and methods:}

This prospective randomized double blind study was conducted after obtaining Institutional Ethics Committee approval and written informed consent. A total of 60 patients of both sexes in the age group 20-60 years belonging to ASA physical status I \& II posted for upper limb orthopedic surgeries were enrolled and randomly divided into three Groups- Group B $(n=20)$, Group BC $(n=20)$ and Group BB $(n=20)$. Patients received solution in the following manner:

GroupB - 0.5\% bupivacaine(isobaric) $100 \mathrm{mg}(20 \mathrm{ml})+20 \mathrm{ml} \mathrm{NS}$.

Group BB $-0.5 \%$ bupivacaine $(20 \mathrm{ml})+0.3 \mathrm{mg}$ Buprenorphine $(1 \mathrm{ml})+19 \mathrm{ml} \mathrm{NS}$

Group BC $-0.5 \%$ bupivacaine $(20 \mathrm{ml})+150 \mathrm{mcg}$ Clonidine $(1 \mathrm{ml})+19 \mathrm{ml} \mathrm{NS}$. 
Patients not willing to be a part of the study, having known allergy or addiction to study drugs, in which regional block was contraindicated in general (local infection, coagulation abnormality and personality disorders or mental illness etc.) or with specific contraindications(pnemothorax or phrenic nerve block) were excluded from the study. Also barred from the study were pregnant or lactating women, those with significant systemic diseases, taking medications with psychotropic or adrenergic activities and chronic analgesic therapy other than simple analgesics (e.g. non-steroidal anti-inflammatory drugs).

In operating theatre standard monitoring including NIBP (non invasive blood pressure), pulse-oximeter and ECG (Electrocardiogram) leads were attached to the patient. Baseline systolic BP (blood pressure), diastolic BP and heart rate along with SPO2 on air and respiratory rate were recorded. An 18G i.v. cannula secured.

Supraclavicular block (Kulenkampff /Classic approach) was given utilizing parasthesia technique without administering any analgesic or sedative drugs to the subjects as premedication. The drug to be used for block was supplied by a concerned person and injected by the researcher totally blinded to the medication being used. After injection of drug and having being assured of complete analgesia surgical procedure was allowed to start. Sensory and motor block of the musculocutaneous, radial, ulnar, and median nerve were determined at frequent intervals after completion of the injection.

The following characteristics of the block were observed:

2.1 Onset time of Sensory block: Pinprick test (time of injection of test drug to reduction of pain at the site of surgery).

2.2 Motor block : Time of onset (times of injection of test drug to development of motor weakness)

: Quality of block (Bromage scale)

2.3 Duration of analgesia: interval between onset of analgesia to the time patient first complains of pain.

2.4Pain : VAS score (0-10scale)

2.5Rescue analgesic (inj.diclofenac $75 \mathrm{mg} \mathrm{im}$ ) : whenever VAS score $\geq 4$

2.6Sedation score

2.7 Side effects: nausea, vomiting, itching, urinary retention etc

2.8 Haemodynamic changes : Bradycardia(pulse $<60$ beats/minute),

hypotension (reduction of MAP $\geq 30 \%$ of baseline), respiratory

depression (respiratory rate $\leq 8$ breaths/minute or arterial oxygen saturation $<90 \%)$.

SEDATION SCORE

0 - Alert, 1 - Awake but sedated, 2 - Asleep but easily aroused,

3 - Asleep and not arousable by verbal contact

\section{Statistical analysis:}

The statistical analysis was performed with "GraphPad Prism version 5.03". Arithmetic mean, median (range), Standard Deviation(SD), Standard error of mean(SEM), carried out as descriptive statistics. ANOVA (with Tukey's, Dunn's, or Bonferroni's test comparison post test) and Chi -square test for qualitative values adopted for analytic and comparative statistics. Post ANOVA multiple comparison test was also performed to compare the groups. A p $<0.05$ was considered to be statically significant.

\section{Results:}

There was no statistically significant difference between the demographic profile (age, sex ratio and body weight), ASA physical status, baseline heart rate and mean arterial pressure of the three groups. The groups were also similar with regard to duration and type of surgery $(p>0.05)$.

Sensory block onset was delayed in clonidine group compared to plain bupivacaine group and the difference is significant,Table-1. This is in contrast to earlier study which shows no effect [12] or faster onset [13]. This needs further evaluation. No difference in onset of sensory block was noted in buprenorphine group as earlier studies $[1,14]$.However significant difference exists when BC compared to BB.

Table - 1 Block characteristics

\begin{tabular}{|l|l|l|l|l|l|}
\hline \multicolumn{2}{|c|}{} & Group B & Group BC & Group BB & P value \\
\hline $\begin{array}{l}\text { Sensory } \\
\text { block } \\
\text { onset } \\
(\mathrm{min})\end{array}$ & Range & $5-10$ & $4-22$ & $5-20$ & $\begin{array}{l}\text { B vs BC (S) } \\
\text { B vs BB } \\
\text { (NS) } \\
\text { BC vs BB }\end{array}$ \\
\hline
\end{tabular}




\begin{tabular}{|c|c|c|c|c|c|}
\hline & & & & & (S) \\
\hline \multirow[b]{2}{*}{$\begin{array}{l}\text { Motor } \\
\text { block } \\
\text { onset }\end{array}$} & Range & $10-25$ & $8-26$ & $10-25$ & \multirow{2}{*}{ 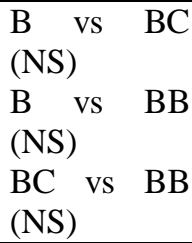 } \\
\hline & Mean \pm SD & $16.75 \pm 4.865$ & $17.05 \pm 6.219$ & $16.25 \pm 4.327$ & \\
\hline \multirow{2}{*}{$\begin{array}{l}\text { Quality } \\
\text { of motor } \\
\text { block }\end{array}$} & $\begin{array}{l}\text { Grade 3(no. } \\
\text { of patients) }\end{array}$ & $7(35 \%)$ & $4(20 \%)$ & $6(30 \%)$ & \multirow{2}{*}{0.5684 (NS) } \\
\hline & $\begin{array}{l}\text { Grade 2(no. } \\
\text { of patients) }\end{array}$ & $13(65 \%)$ & $16(80 \%)$ & $14(70 \%)$ & \\
\hline \multirow[b]{2}{*}{$\begin{array}{l}\text { Duration } \\
\text { of } \\
\text { analgesia }\end{array}$} & Range & $180-630$ & 250-990 & $390-1830$ & \multirow{2}{*}{$\begin{array}{l}\text { B vs } \quad \text { BC } \\
(\mathrm{NS}) \\
\mathrm{B} \text { vs BB } \\
<0.001(\mathrm{~S}) \\
\mathrm{BC} \text { vs BB } \\
<0.05(\mathrm{~S})\end{array}$} \\
\hline & Mean \pm SD & $369.3 \pm 111.5$ & $578.5 \pm 201.3$ & $822.8 \pm 417.5$ & \\
\hline
\end{tabular}

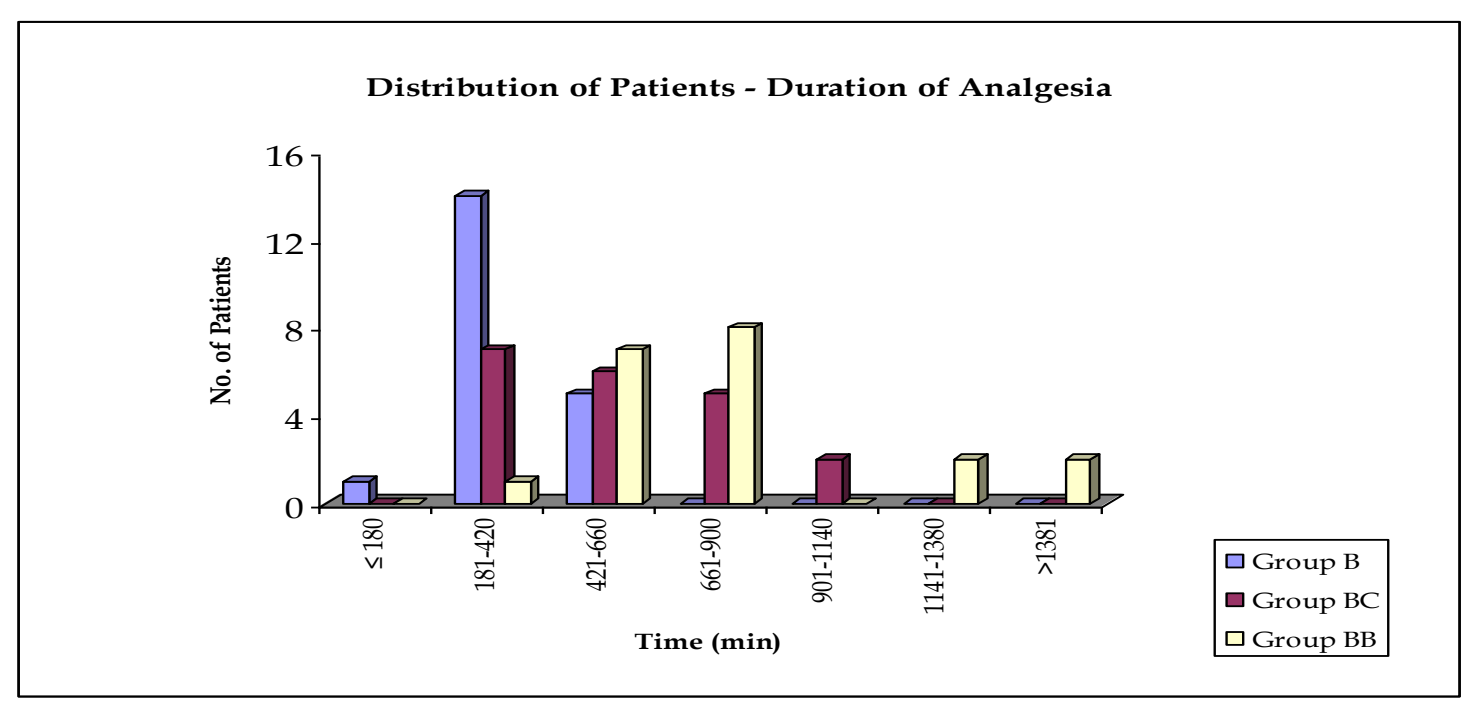

Fig.1 - Distribution of Patients according to Duration of Analgesia

Motor block onset and quality of motor block showed no difference among the three groups, Table-1. However one study does show lower score post-operatively (after $240 \mathrm{~min}$ ) with clonidine compared to plain bupivacaine [13].

Duration of analgesia as evaluated by onset of pain was prolonged in clonidine group to as long as 990min and buprenorphine group to $1830 \mathrm{~min}$ compared to plain bupivacaine, Table-1, Fig.-1. However the difference was statistically significant with buprenorphine group and when group BC and BB are compared. A wide variation may be responsible for the same.

VAS score was 0 till 4 hours in all groups however it is significantly lower in clonidine and bupivacaine group at 5 hours onward indicating prolongation of analgesia, Table-2, Fig.-2.

Table - 2 Distribution of Patients according to VAS score

\begin{tabular}{|l|l|l|l|l|l|l|}
\hline \multirow{2}{*}{$\begin{array}{l}\text { Time } \\
\text { (in } \\
\text { Hrs })\end{array}$} & \multicolumn{4}{|c|}{ VAS score } & \multicolumn{4}{c|}{$\begin{array}{l}\text { Group } \\
\text { B }\end{array}$} & $\begin{array}{l}\text { Group } \\
\text { BC }\end{array}$ & $\begin{array}{l}\text { Group } \\
\text { BB }\end{array}$ & $\begin{array}{l}\text { P value , (B vs } \\
\text { BC) }\end{array}$ & $\begin{array}{l}\text { P value , (B vs } \\
\text { BB })\end{array}$ & $\begin{array}{l}\text { P value , (BC vs } \\
\text { BB })\end{array}$ \\
\hline $\begin{array}{l}1,2,3,4 \\
\mathrm{hr}\end{array}$ & $0(0-0)$ & $0(0-0)$ & $0(0-0)$ & Ns & Ns & $\mathrm{ns}$ \\
\hline $5 \mathrm{hr}$ & $0(0-3)$ & $0(0-2)$ & $0(0-0)$ & $<0.05$ & $0.001-0.01$ & $\mathrm{~ns}$ \\
\hline $6 \mathrm{hr}$ & $\begin{array}{l}0.5(0- \\
5)\end{array}$ & $0(0-4)$ & $0(0-0)$ & $\mathrm{Ns}$ & $<0.001$ & $\mathrm{~ns}$ \\
\hline $8 \mathrm{hr}$ & $2(0-6)$ & $0(0-5)$ & $0(0-3)$ & $<0.001$ & $<0.001$ & $\mathrm{~ns}$ \\
\hline
\end{tabular}


Comparative study of effects of buprenorphine or clonidine as adjuvants to local anesthetics

\begin{tabular}{|l|l|l|l|l|l|l|}
\hline $10 \mathrm{hr}$ & $4(0-5)$ & $0.5(0-6)$ & $0(0-5)$ & $0.001-0.01$ & $<0.001$ & $\mathrm{~ns}$ \\
\hline $12 \mathrm{hr}$ & $\begin{array}{l}3.5(2- \\
6)\end{array}$ & $2(0-4)$ & $2(0-5)$ & $0.001-0.01$ & $0.001-0.01$ & $\mathrm{~ns}$ \\
\hline $16 \mathrm{hr}$ & $3(1-6)$ & $3.5(0-6)$ & $3.5(0-5)$ & $\mathrm{Ns}$ & $\mathrm{Ns}$ & $\mathrm{ns}$ \\
\hline $20 \mathrm{hr}$ & $5(2-6)$ & $3.5(2-6)$ & $3(0-5)$ & $\mathrm{Ns}$ & $\mathrm{Ns}$ & $\mathrm{ns}$ \\
\hline $24 \mathrm{hr}$ & $3(3-6)$ & $3(2-6)$ & $3(0-5)$ & $\mathrm{Ns}$ & $\mathrm{Ns}$ & $\mathrm{ns}$ \\
\hline
\end{tabular}

* Pain score (Visual Analogue Scale) - values in median (range)

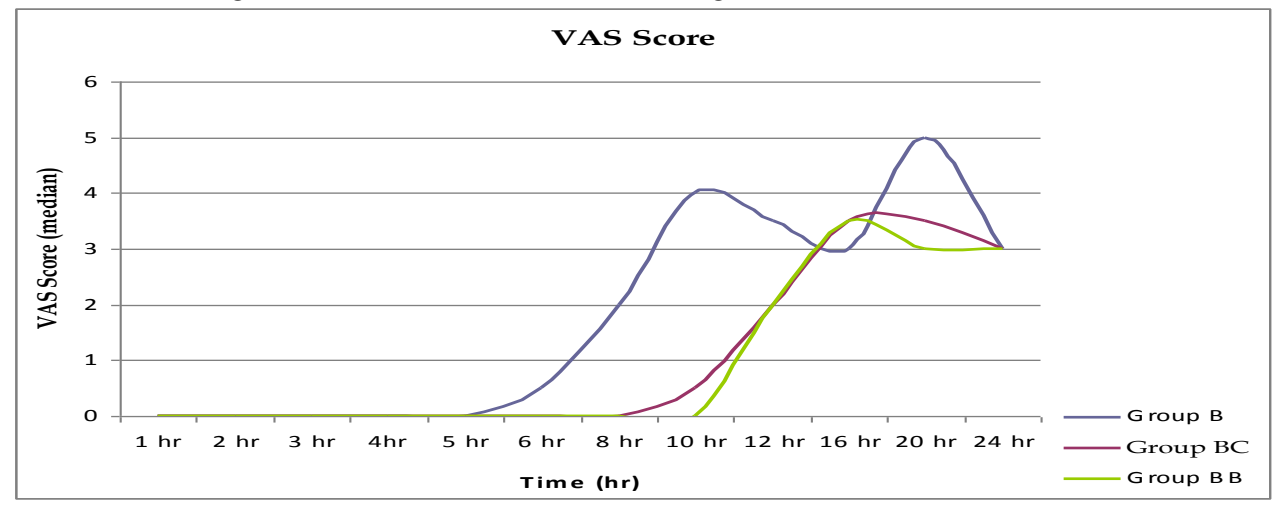

Fig.2 - Distribution of Patients according to VAS Score during 24 hours

Time to first rescue analgesic is also delayed up to 6 hour in clonidine group and 10 hours in buprenorphine group due to lower VAS score, Table-3, Fig.-3.

Table - 3 Distribution of Patients according to Time for First Rescue Analgesic (Diclofenac)

\begin{tabular}{|l|l|l|l|}
\hline Time (in Hrs) & Group B , (no. of patients) & Group BC, (no. of patients) & Group BB, (no. of patients) \\
\hline$<6$ & $1(5 \%)$ & $0(0 \%)$ & $0(0 \%)$ \\
\hline $6-12$ & $19(95 \%)$ & $6(30 \%)$ & $5(25 \%)$ \\
\hline $13-18$ & $0(0 \%)$ & $7(35 \%)$ & $8(40 \%)$ \\
\hline $19-24$ & $0(0 \%)$ & $7(35 \%)$ & $5(25 \%)$ \\
\hline$>24$ & $0(0 \%)$ & $0(0 \%)$ & $2(10 \%)$ \\
\hline Total & 20 & 20 & 20 \\
\hline Range & $4-10$ & $6-20$ & $10-34$ \\
\hline Median & 10 & 16 & 16 \\
\hline Mean \pm SD & $9 \pm 2.791$ & $15.3 \pm 4.78$ & $18 \pm 6.391$ \\
\hline SEM & 5.538 & 1.069 & 1.429 \\
\hline P value & B vs BC $-<0.001(* * *), B$ vs BB $-<0.001(* * *), B C$ vs BB $->0.05$ (ns) \\
\hline
\end{tabular}




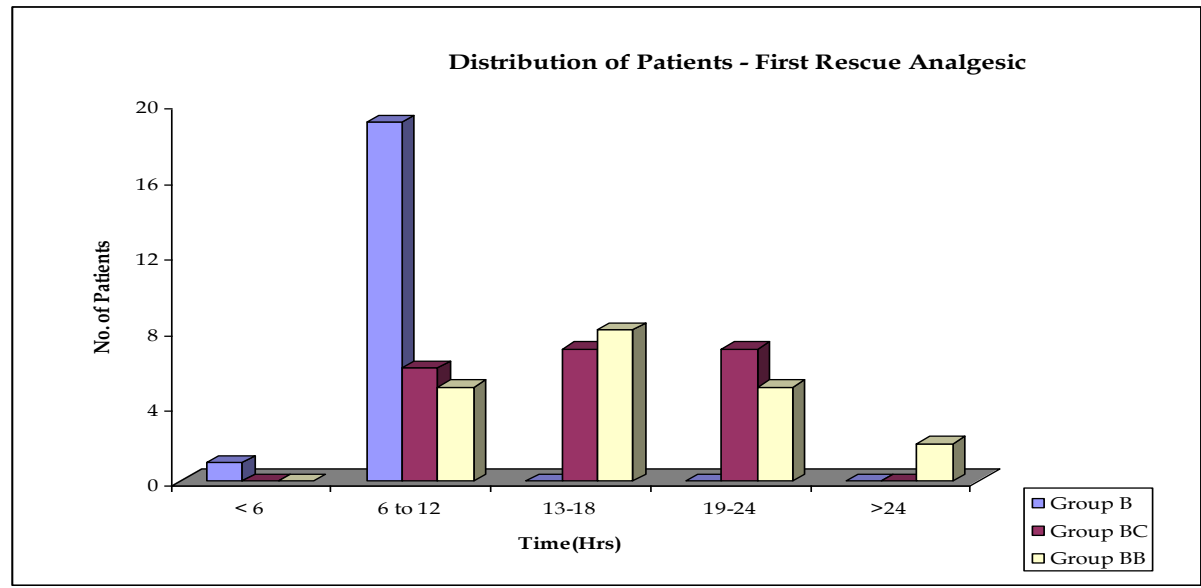

Fig.3 - Distribution of Patients according to First Rescue Analgesic

Up to $40 \%$ of patient in group B required 3 rescue analgesic in 24 hour period, Table - 4, Fig.- 4. However in $10 \%$ in group $\mathrm{BC}$ and $5 \%$ in group $\mathrm{BB}$ required so.

Table4 Distribution of Patients according to Total Doses of Analgesic (Diclofenac) required in $24 \mathrm{hr}$

\begin{tabular}{|c|c|c|c|}
\hline Doses of analgesic & Group B (no. of patients) & Group BC (no. of patients) & Group BB (no. of patients) \\
\hline 1 & $2(10 \%)$ & $14(70 \%)$ & $11(55 \%)$ \\
\hline 2 & $9(45 \%)$ & $3(15 \%)$ & $6(30 \%)$ \\
\hline 3 & $8(40 \%)$ & $2(10 \%)$ & $1(5 \%)$ \\
\hline 4 & $1(5 \%)$ & $1(5 \%)$ & $0(0 \%)$ \\
\hline Total & 20 & 20 & 20 \\
\hline Range & $1-4$ & $1-4$ & $0-3$ \\
\hline Median & 2 & 1 & 1 \\
\hline Mean \pm SD & $2.4 \pm 0.7539$ & $1.5 \pm 0.8885$ & $1.3 \pm 0.7327$ \\
\hline SEM & 0.1686 & 0.1987 & 0.1638 \\
\hline $\mathrm{P}$ value & \multicolumn{3}{|c|}{$\mathrm{B}$ vs $\mathrm{BC}-0.001-0.01(* *), \mathrm{B}$ vs $\mathrm{BB}-<0.001(* * *), \mathrm{BC}$ vs $\mathrm{BB}->0.05(\mathrm{~ns})$} \\
\hline
\end{tabular}

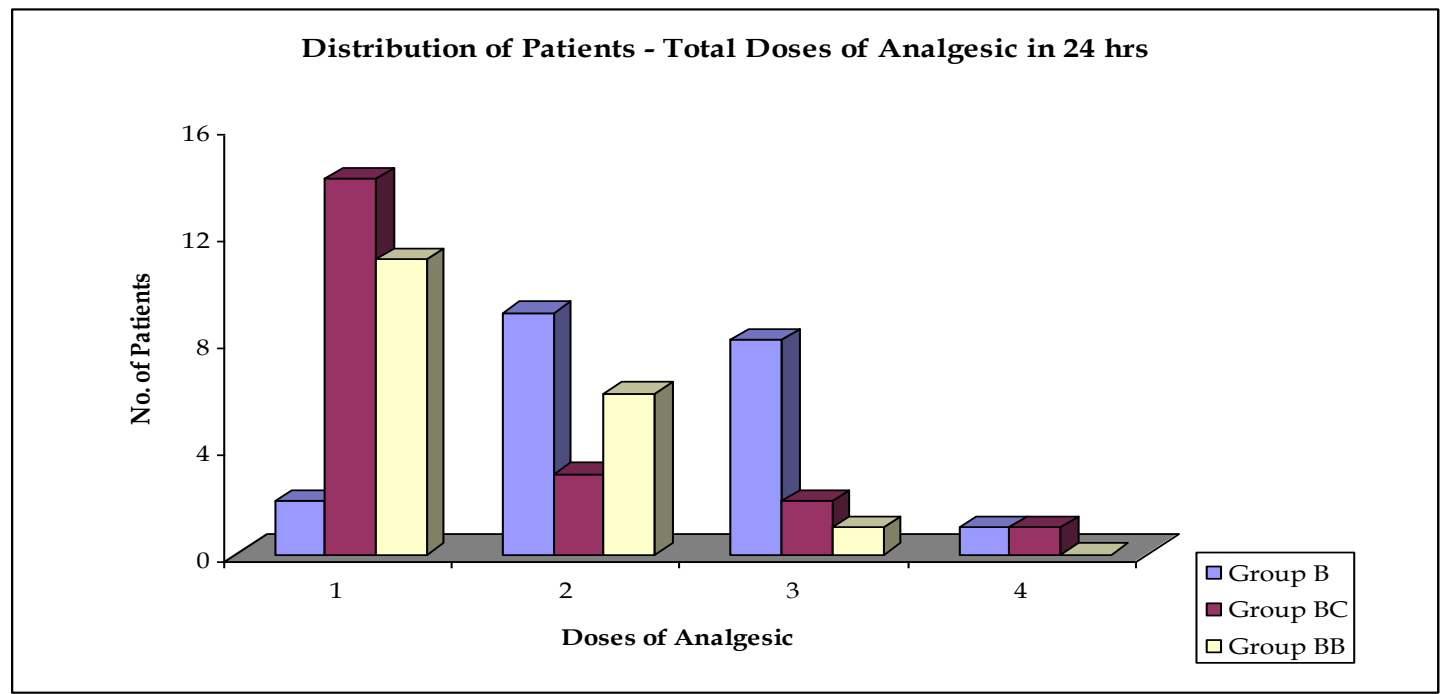

Fig.4- Distribution of patients according to total Doses of analgesic in $24 \mathrm{hrs}$

Sedation as side effect was encountered in $40 \%$ in group BB compared to 5\% showed in BC group. Also higher sedation score was achieved in buprenorphine group compared to clonidine group, Fig.-5. 


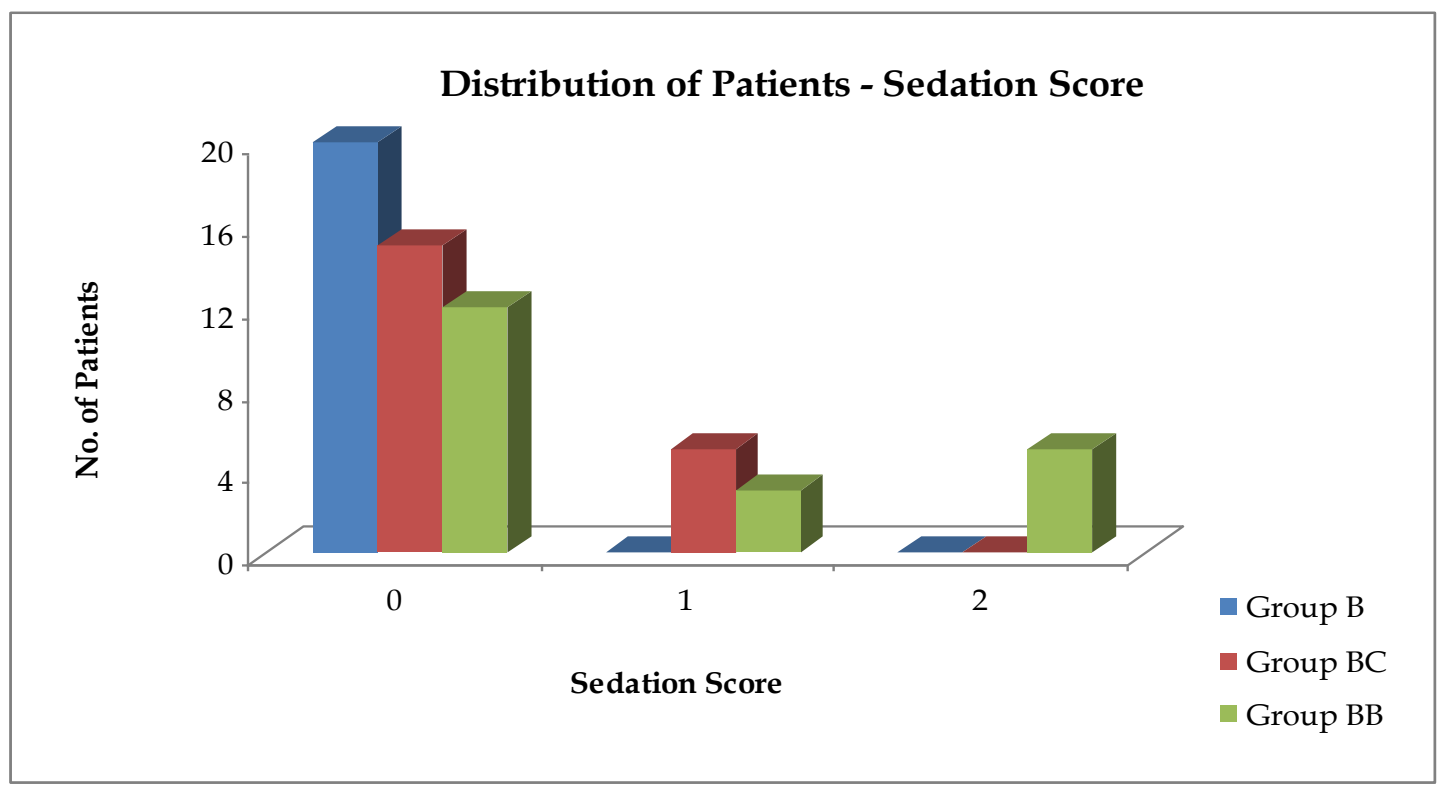

Fig. 5- Distribution of Patients according to Complications

Two patients' also encountered pruritis in buprenorphine group, Fig.-6. Nausea and vomiting were encountered in all 3 groups but its incidence was higher in buprenorphine group though difference was statistically insignificant. None showed signs of hemodynamic instability, local anesthetic toxicity or respiratory depression.

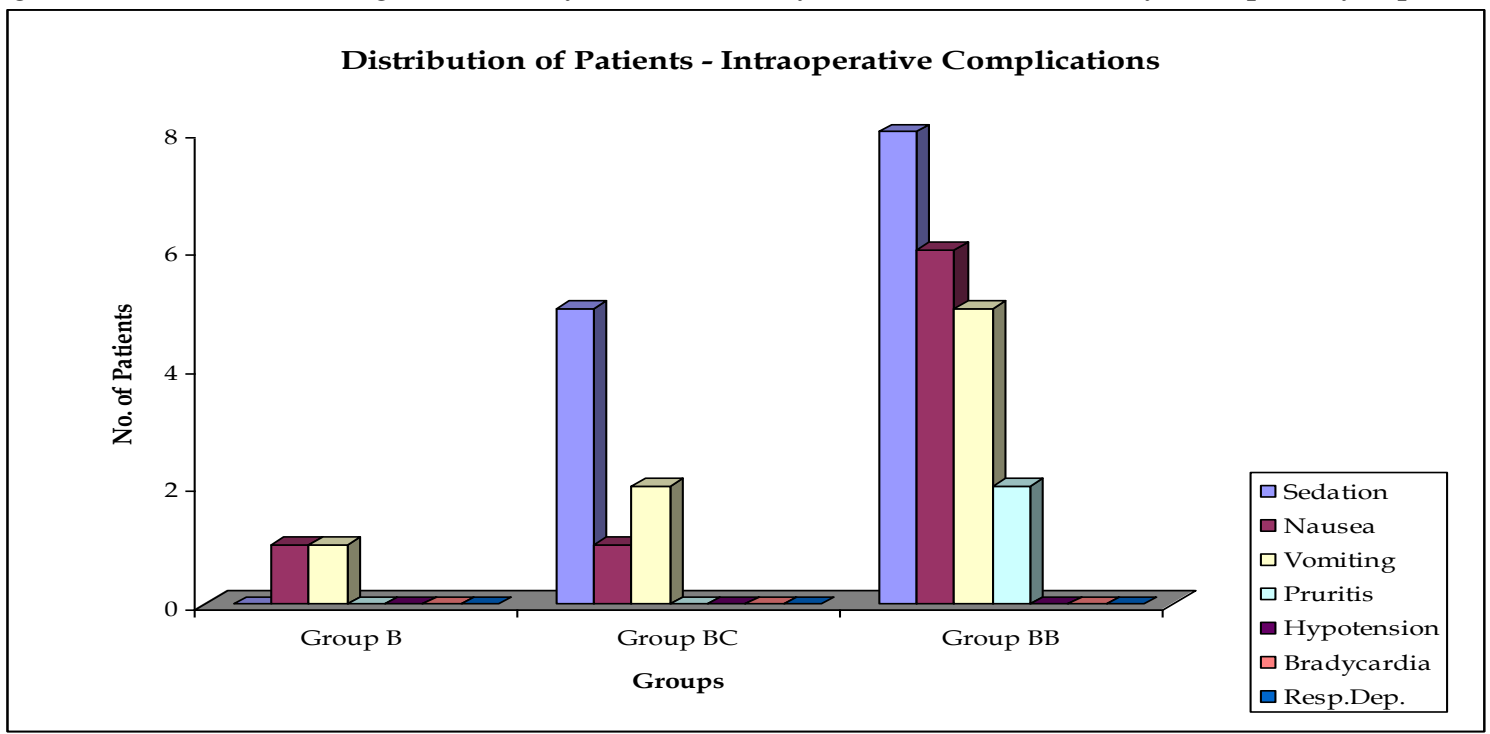

Fig. 6- Distribution of Patients according to Complications

\section{Discussion:}

We observed that clonidine $150 \mu \mathrm{g}$ added to a $0.25 \%$ bupivacaine in brachial block as an adjuvant leads to no significant prolongation of duration of analgesia .It however does decrease analgesic consumption, prolonged the time for first rescue analgesic and lower VAS scores indicating that clonidine modified pain mechanics to some extent. No significant side effects were observed.

On the other hand addition of Buprenorphine $(0.3 \mathrm{mg})$ to bupivacaine $(0.25 \%$ buprenorphine, $40 \mathrm{ml})$ in brachial plexus block produced effective analgesia which lasted longer than the two other groups (more than twice as long as that produced by local anesthetic alone) with no difference in sensory or motor onset time ,reduced pain scores (VAS) and less supplemental analgesics. Some usual side effects of opioids are observed, but are mild.

5.1 Duration of analgesia In studies with clonidine, difference in opinion exists with regard to prolongation of postoperative analgesia when clonidine was added to local anesthetic for brachial plexus block ${ }^{[5-8,10-11]}$. Some trials have showed benefit from the use of clonidine ${ }^{[10,15,16]}$ with ${ }^{[6]}$ or without ${ }^{[5,7,8]}$ control group. Also includes brachial plexus block studies with $0.25 \%$ bupivacaine ${ }^{[10,17]}$ and $0.5 \%$ bupivacaine ${ }^{[18,19]}$. Others observed ${ }^{[19-21]}$ no significant difference in duration with the use of clonidine both in studies with ${ }^{[22]}$ or without ${ }^{[10,11]}$ control group. Our results correlate with later studies. 
The following may explain the reason for the observed differences.

5.1.1. The type and the concentration of the local anesthetics: Those who observed significant effects of clonidine investigated local anesthetics of short or intermediate duration of action. Clonidine, because of a long elimination half-life ${ }^{[16]}$, could have improved the analgesic efficacy of these solutions. Those who did not observe analgesic most were with large dose of a long-lasting local anesthetic, which could have masked the effects of clonidine on the nerve block. In our study we used long acting LA but reduced the concentration to $0.25 \%$.

5.1.2. Type of surgery: The previous studies in which clonidine prolonged the pain-free period investigated mainly outpatients undergoing minor hand and forearm surgery associated with mild to moderate postoperative pain. In contrast, our patients underwent all type of surgeries, some of which induces severe postoperative pain and requires intensive analgesic medication.

5.1.3. Individual's threshold for bearing pain.

With regard to buprenorphine group, in a similar study conducted by Viel EJ.et.al. ${ }^{[1]}$ with $40 \mathrm{ml}$ of $0.5 \%$ bupivacaine the duration of analgesia is $35 \mathrm{~h}(35.05 \pm 1.95)$. Boogaerts $\mathbf{J}$ et.al. ${ }^{[14]}$ reported duration of analgesia to be 24 hours with buprenorphine $0.15 \mathrm{mg}$. With $0.25 \%$ bupivacaine as local anesthetic and $0.3 \mathrm{mg}$ buprenorphine in our study, the mean duration with buprenorphine was $822.8 \mathrm{~min}(13.71 \mathrm{hr})$. In our study 6 of the 20 patients' concerned experienced relief from pain for more than $14 \mathrm{hr}$ and 2 were pain free for more than $24 \mathrm{hr}$. When groups BC and BB are compared for duration of analgesia, difference is significant.

5.2 Variation in duration of analgesia - As far as duration of analgesia is concerned in our study we observed a wide range (clonidine 250-990 min, buprenorphine 390-1830 $\mathrm{min}$ ). In previous peripheral block studies that reported a significant effect with clonidine, a similar tendency to variability of duration of block in the groups containing clonidine exists ${ }^{[5,7,10,19]}$.

Several explanations are possible for the scattered distribution of duration of block in the groups.

5.2.1. Inter-patient variations in the anatomy of the plexus sheath or plexus nerves ${ }^{[23]}$ : There was no correlation of patient characteristics (i.e. body weight, sex) with duration of block in the groups, suggesting that differences in these characteristics are not responsible for the broad scattering.

5.2.2. Block technique. Local anaesthetics spread differently in the plexus sheath depending on the block technique, resulting in different concentrations of drug at the nerve ${ }^{[23]}$. We in our study used single injection technique but among other studies using a multiple injection technique ${ }^{[22,24]}$, only one reported a consistently prolonging effect with clonidine ${ }^{[24]}$.

5.2.3. The unclear mechanism of action of clonidine and buprenorphine in peripheral nerve blocks. Many hypotheses have been proposed for clonidine such as local vasoconstriction ${ }^{[6,10,11]}$, a direct action on the nerve ${ }^{[25-27]}$, or a systemic effect ${ }^{[6,28,29]}$. Also mechanism of action of opioids at the peripheral nerve level is still uncertain.

5.2.3.1. Traditional belief - opioids act exclusively within central nervous system.

5.2.3.2. Isolation of opioid receptor from the brachial plexus fibers of rats ${ }^{[30]}$ has favoured role of opioid at peripheral level ${ }^{[31]}$.

5.2.3.3. The electrophysiological studies have suggested that opioids may exert a nonspecific action on the nerves by impairing sodium and potassium conduction.

5.2.3.4. Central migration of opioids to the neurons of the dorsal horn is possible.

5.2.3.5. Local action at site of injection is also favored by the studies which report plasma concentration of opioid to be below the threshold for adequate analgesia ${ }^{[32-34]}$.

Onset of Sensory Block - Our results showed delayed onset of sensory block in clonidine group (12.05 min) compared to plain bupivacaine group $(8.45 \mathrm{~min})$ and difference is significant. These findings are in not in accord with those of previous trials most of which showed no significant difference in sensory onset time between the groups ${ }^{[7,8,10-11,18,20-22,24]}$. In one study conducted by Bernard et al. ${ }^{[5]}$ reduced sensory block onset time was observed with small doses of clonidine 30-90 $\mu \mathrm{g}$ in combination with lidocaine administered with axillary block. The differences may be attributed to local anesthetic differences in type, concentration and total drug amount compared to our study.

In our study duration of onset of sensory block showed no statistically significant difference between buprenorphine group and plain LA group. When clonidine and buprenorphine group are compared onset of sensory block significant difference exist.

Our study showed no significant difference in onset of motor block when plain local anaesthetic was compared with clonidine group in accord with those of previous trials ${ }^{[7,8,10-11,18,20-22,24]}$. Motor block onset and quality of motor block in buprenorphine group were no different from the other two groups in our study. We could not find any study documenting any changes in these variables with addition of opioids. Also when clonidine and buprenorphine group are compared difference is insignificant.

The study of changes in VAS scores show that in clonidine group, pain scores (VAS 0-10) were higher $10 \mathrm{hr}$ after the block (median 0.5; range 0-6) than with plain bupivacaine (at $6 \mathrm{hr}$, Median 0.5, range 0-5). At all point 
of time VAS was low in score in clonidine group then in group with bupivacaine alone except at $24 \mathrm{hr}$ at which VAS score were equal. The variations were significant at $5 \mathrm{hr}, 8 \mathrm{hr}, 10 \mathrm{hr}$ and $12 \mathrm{hr}$.

In the $24 \mathrm{hr}$ postoperative study period, group BC required approximately $2 / 3$ as many doses (mean $1.5 \pm 0.8885$ doses) of supplemental analgesics as group B patients (mean 2.4 \pm 0.7539 ). Also the time for first rescue analgesic $(15.3 \pm 4.78 \mathrm{hr})$ was very much significantly prolonged then plane bupivacaine group $(9 \pm 2.791 \mathrm{hr})$.

Vas score were lower in group with buprenorphine than without it at all times except at 24 hour at which the three groups showed no difference between them. Some of the earlier studies report similar results ${ }^{[34,}$ ${ }^{35]}$ while others state no difference ${ }^{[36]}$.

The total requirement of analgesics was reduced significantly $(1.3 \pm 0.7327$ vs. $2.4 \pm 0.7539$ for group B) and the time to first analgesic prolonged with the addition of opioids.

Haemodynamic (HR, NIBP) and respiratory parameters (Spo2 and RR) observation showed that neither hypotension, nor bradycardia or respiratory depression was noted in clonidine group. This was in accordance with result observed in some of the studies ${ }^{[7]}$. Some studies reported significant arterial hypotension ${ }^{[5,11]}$ and/or bradycardia ${ }^{[8,11]}$, whereas others did not ${ }^{[6,7,10]}$. Macaire et al. ${ }^{[5]}$ reported "a slight but significant sedation" without any associated hypotension or bradycardia albeit when $300 \mu \mathrm{g}$ clonidine was used. In our study we did encountered sedation in 5 of the 20 patients but it was of low sedation score and also on stastical evaluation these were found to be insignificant.

No serious side-effects are reported in buprenorphine group study. Of those observed (sedation, nausea, vomiting, pruritis, dryness of mouth) (fig.5), their incidence was similar to that reported previously ${ }^{[1,4,32,36-37]}$. The most common side-effect observed in our study is sedation. None showed any respiratory depression. The systemic effects indicate partial systemic resorption. This absorption could explain the longer duration of analgesia in the buprenorphine group.

\section{Conclusion:}

Thus both buprenorphine and clonidine have been found to have favourable effect on brachial block characteristics with acceptable side effects though significant prolongation of duration of analgesia is seen with buprenorphine alone.

\section{References :}

[1] Viel EJ, Eledjam JJ, De La Coussaye J, D'Athis F. Brachial plexus block with opioids for postoperative pain relief: comparison between buprenorphine and morphine. Reg Anesth 1989; 14: 274-8.

[2] Candido KD, Franco CD, Khan MA, Winnie AP, Raja DS. Buprenorphine added to the local anesthetic for brachial plexus block to provide postoperative analgesia in outpatients.Reg Anesth Pain Med.2001 Jul-Aug;26(4):352-6.

[3] Candido KD, Winnie AP, Ghaleb AH, Fattouh MW, Franco CD. Buprenorphine added to the local anesthetic for axillary brachial plexus block prolongs postoperative analgesia. Regional Anesthesia and Pain Medicine, Volume 27, Issue 2, Pages 162 - 167.

[4] Bazin JE, Massoni C, Bruelle P, et al. The addition of opioids to local anaesthetics in brachial plexus block: the comparative effects of morphine, buprenorphine and sufentanil. Anaesthesia 1997; 52:858-62.

[5] Bernard JM, Macaire P. Dose-range effects of clonidine added to lidocaine for brachial plexus block. Anesthesiology 1997; 87: 27784 .

[6] Singelyn FJ, Dangoisse M, Bartholomee S, Gouverneur JM. Addingclonidine to mepivacaine prolongs the duration of anesthesiaand analgesia after axillary brachial plexus block. RegAnesth 1992; 17:148 -50.

[7] Singelyn FJ, Gouverneur J, Robert A. A minimum dose of clonidine added to mepivacaine prolongs the duration of anesthesia and analgesia after axillary brachial plexus block. Anesth Analg 1996; 83:1046 -50.

[8] Buttner J, Ott B, Klose R. Der einflub von clonidinzusatz zu mepivacain. Anaesthesist 1992; $41: 548$-54. 15. Singelyn FJ, Dangoisse M, Bartholomee S, Gouverneur JM. Adding clonidine to mepivacaine prolongs the duration of anesthesia and analgesia after axillary brachial plexus block. Reg Anesth 1992s; 17:148 -50.

[9] Bone HG, Van Aken H, Brooke M, et al. Enhancement of axillary brachial plexus block anaesthesia by coadministration of neostigmine. Reg Anesth Pain Med 1999;24:405-10.

[10] Eledjam JJ, Viel E, Charavel P, du Cailar J. Brachial plexus block with bupivacaine: effects of added alpha-adrenergic agonists: comparison between clonidine and epinephrine. Can J Anaesth 1991; 38:870 - 5 .

[11] Gaumann D, Forster A, Griessen M, et al. Comparison between clonidine and epinephrine admixture to lidocaine in brachial plexus block. Anesth Analg 1992;75:69-74.

[12] Bazin JE, Massoni C, Groslier D, et al. Bloc du plexus brachial :effet de l'addition de sufentanil au melange d'anethesiques locaux sur la duree de l'analgesie postoperatoire. Ann Fr Anesth. Reanim 1997;16:9 -13.

[13] Shivinder Singh,Amitabh Aggarwal.A randomised controlled double-blinded prospective study of the efficacy of clonidine added to bupivacaine as compared with bupivacaine alone used in supraclavicular brachial plexus block for upper limb surgeries.Indian Journal of Anesthesia; Vol.54:2010:552-556.

[14] 14.Boogaerts J, Balatoni E,Lafont N,Lecron L,Vanderhaegen JJ. Utilisation des morphiniques dans les blocs nerveux peripheriques. Ars Medici Congress Series 1982;3:143-151

[15] Murphy DB, McCartney CJL, Chan VWS. Novel analgesic adjuncts for brachial plexus block: A systematic review. Anesth Analg 2000;90:1122-8

[16] Eisenach JC, De Kock Marc, Klimscha W. $\boldsymbol{\alpha}_{2}$-Adrenergic agonists for regional anesthesia. A clinical review of clonidine (19841995). Anesthesiology 1996:85: 655-74.

[17] 17.Hutschala D, Mascher H, Schmetterer L, Klimscha W, Fleck T , Eicher HG, Tschernko EM. Clonidine added to bupivacaine enhances and prolongs analgesia after brachial plexus block via a local mechanism in healthy volunteers. Eur J Anaesthesiol 2004;21:198-204. 
[18] Wolfgang Erlacher,Christoph Schuschnig, Herbert Koinig, Peter Marhofer, Matthias Melischek, Nikolaus Mayer, and Stephan Kapral, . Clonidine as adjuvant for mepivacaine, ropivacaine and bupivacaine in axillary, perivascular brachial plexus block. Can J Anaesth 2001;48:522-5.

[19] Duma A, Urbanek B, Sitzwohl C, , A. Kreiger, M. Zimpfer, and S. Kapral. Clonidine as an adjuvant to local anaesthetic axillary brachial plexus block: a randomized, controlled study. Br J Anaesth 2005; 94:112-16.

[20] Erlacher W, Schuschnig C, Orlicek F, et al. The effects of clonidine on ropivacaine $0.75 \%$ in axillary perivascular brachial plexus block. Acta Anaesthesiol Scand 2000; 44: 53-7.

[21] Sia S, Lepri A. Clonidine administered as an axillary block does not affect postoperative pain when given as the sole analgesic. Anesth Analg 1999; 88: 1109-12.

[22] Culebras X, Van Gessel E, Hoffmeyer P, Gamulin Z. Clonidine combined with a long acting local anesthetic does not prolong postoperative analgesia after brachial plexus block but does induce hemodynamic changes. Anesth Analg 2001; 92: 199-204.

[23] 23. Winnie AP. Brachial Plexus Block. In: Winnie AP, ed. Plexus Anesthesia Vol 1. Philadelphia: W.B. Saunders, $1993 ; 117-88$.

[24] AH El Saied, MP Steyn and JM Ansermino Clonidine prolongs the effect of ropivacaine for axillary brachial plexus blockade.article7, Canadian Journal of Anesthesia, Vol 47, 962-967.

[25] Gaumann DM, Brunet PC, Jirounek P. Clonidine enhances the effects of lidocaïne on C-fiber action potential. Anesth Analg 1992; 74: 719-25.

[26] 26. Butterworth JF, Strchartz GR. The 2-adrenergic agonists clonidine and guanfacine produce tonic and phasic block of conduction in rat sciatic nerve fibers. Anesth Analg 1993; 76: 295-301.

[27] Gaumann DM, Brunet PC, Jirounek P. Hyperpolarizing afterpotentials in C fibers and local anesthetic effects of clonidine and lidocaine. Pharmacology 1994; 48: 21-9.

[28] Bernard J-M, Kick O, Bonnet F. Comparison of intravenous and epidural clonidine for postoperative patient controlled-analgesia. Anesth Analg 1995; 81: 706-12.

[29] Eisenach JC, Detweiler M, Hood D. Hemodynamic and analgesic actions of epidurally administered clonidine. Anesthesiology 1993; 78: $525-31$

[30] 30.Brooks JHJ,GuptaB. Futher evidence for narcotic receptors in human peripheral nerves. Regional Anesthesia 1990;15:215

[31] Stein C. Control of pain in peripheral tissue by opioids New England journal of Medicine 1995;332:1685-90

[32] Gobeaux D, Landais A, Bexon G, et al. Addition of fentanyl to adrenalised lidocaine for the brachial plexus block. Cah Anesthesiol 1987; 35:195-9.

[33] Gormley WP, Murray JM, Fee JPH, Bower S. Effect of the addition of alfentanil to lignocaine during axillary brachial plexus anaesthesia. Br J Anaesth 1996;76:802-5.

[34] 34. Wajima Z, NakajimaY, Kim N, et al. IV compared with brachial plexus infusion of butorphanol for postoperative analgesia. Br J Anaesth 1995;74:392-5.

[35] 35. Kardash K, Schools A, Conception M. Effects of brachial plexus fentanyl on supraclavicular block. Reg Anesth 1995;20:311-5.

[36] 36. Bourke DL, Furman WR. Improved postoperative analgesia with morphine added to axillary block solution. J Clin Anesth 1993; $5: 114-7$.

[37] 37. Gobeaux D, Landais A. Use of two opioids in blocks of the brachial plexus. Cah Anesthesiol 1988;36:437-40. 